\title{
Ciência da Informação: demarcação teórico-disciplinar e as interações interdisciplinares com a Biblioteconomia'
}

\author{
Information Science: Theoretical-disciplinary \\ delimitation and interdisciplinary \\ interactions with Library Science
}

\author{
Ana Paula Lima dos SANTOS² \\ Mara Eliane Fonseca RODRIGUES 3
}

\section{Resumo}

O propósito deste trabalho é refletir acerca da temática interdisciplinaridade, a fim de garantir a compreensão das principais questões envolvidas nesse processo. Para tanto, em um primeiro momento, apresenta diferentes interpretações que buscam explicar a constituição da Ciência da Informação sob uma perspectiva teórico-disciplinar, com o objetivo de melhor compreender a sua natureza constitutiva. Em seguida, a partir de enfoques interpretativos de alguns teóricos da Ciência da Informação, procura evidenciar os elementos que a caracterizam como uma disciplina interdisciplinar, ressaltando suas relações com a Biblioteconomia. Busca, ainda, identificar os elos interdisciplinares entre os dois campos, por meio da análise das interpretações manifestadas pelos principais teóricos da Ciência da Informação. Conclui que a Biblioteconomia e a Ciência da Informação têm uma característica comum: facilitar o acesso à informação - e que os pesquisadores da área podem desenvolver por meio desse elo comum uma prática interdisciplinar.

Palavras-chave: Biblioteconomia. Ciência da informação. Interdisciplinaridade.

\begin{abstract}
The purpose of this paper was to reflect on interdisciplinary issues to promote the understanding of the main issues involved in this process. For this purpose, we first discuss the different interpretations that seek to explain the foundations of Information Science from a theoretical, disciplinary perspective to better understand its constitutive nature. Then, from an interpretative approach of theoretical Information Science, we seek to highlight the elements that characterize it as an interdisciplinary discipline, emphasizing its relations with Library Science. We also endeavor to identify interdisciplinary connections between the two fields through the analysis of interpretations expressed by main the theorists in Information Science. We also endeavor to identify interdisciplinary connections between the two fields through the analysis of interpretations expressed by main the theorists in Information Science. We conclude that Library Science and Information Science have common features: they facilitate access to information and researchers can develop interdisciplinary practice through this common bond.

Keywords: Library science. Information science. Interdisciplinary practice/approach.

\footnotetext{
1 Artigo elaborado a partir da dissertação de mestrado de A.P.L. SANTOS, intitulada"Relações interdisciplinares entre a Ciência da Informação e a Biblioteconomia: limites e possibilidades". Universidade Federal Fluminense, 2012.

2 Universidade Federal Fluminense, Superintendência de Documentação. R. Marcos Waldemar de Freitas Reis, s/n., Prédio da Biblioteca Central, Campus do Gragoatá, 24210-201, Niterói, RJ, Brasil. Correspondência para/Correspondence to: A.P.L. SANTOS. E-mail: <annasorriso@ig.com.br>.

3 Universidade Federal Fluminense, Programa de Pós-Graduação em Ciência da Informação. Niterói, RJ, Brasil.

Recebido em 5/10/2012, reapresentado em 29/5/2013 e aceito para publicação em 3/7/2013.
} 


\section{Introdução}

O propósito do presente trabalho é refletir acerca da temática interdisciplinaridade, a fim de garantir a compreensão das principais questões envolvidas nesse processo. Nessa perspectiva, procura aprofundar a análise desta abordagem a partir das relações entre as áreas da Ciência da Informação e da Biblioteconomia. As reflexões apresentadas fazem parte de uma pesquisa realizada, com base no posicionamento dos estudiosos dessa temática, no qual se propôs a discutir: "A questão da interdisciplinaridade entre diferentes campos do conhecimento, notadamente a Ciência da Informação e a Biblioteconomia" (Santos, 2012, p.12).

Esta preocupação surgiu devido à constatação de que vários autores reconhecem a Ciência da Informação como um campo interdisciplinar e, dentre as disciplinas com as quais mantém relações interdisciplinares, a Biblioteconomia é apontada como aquela que apresenta um forte laço interdisciplinar com a área. Uma vez que a literatura indica que a relação da Biblioteconomia com a Ciência da Informação é intensa, resolveu-se investigar os elos interdisciplinares entre as duas áreas.

Para tanto, em um primeiro momento, procura-se mostrar as diferentes interpretações que buscam explicar a constituição da Ciência da Informação sob uma perspectiva teórico-disciplinar, com o objetivo de melhor compreender a sua natureza constitutiva. Em um segundo momento, tenta-se evidenciar os elementos que caracterizam a Ciência da Informação como uma disciplina interdisciplinar. Em seguida, busca-se identificar os elos interdisciplinares entre os dois campos, por meio da análise das interpretações manifestadas pelos principais teóricos da Ciência da Informação. Por fim, apresenta-se as reflexões finais sobre a temática aqui discutida.

\section{Ciência da Informação: interpretações teórico-disciplinares}

Para alguns autores, o marco do aparecimento da Ciência da Informação como um campo de conhecimento foram as reuniões do Georgia Institute of Technology, ocorridas em outubro de 1961 e em abril de 1962, "Quando foi pela primeira vez formulado um conceito para a área e discutidos a formação deste novo profissional, cursos e disciplinas" (Pinheiro, 2005, p.2).

Para outros, o início da Ciência da Informação pode ser demarcado pela adoção do termo Informação Científica. Nesse caso, a Conferência de Informação Científica, realizada na Royal Society, em 1948, ou 10 anos depois a Conferência de Informação Científica, realizada em Washington, seriam indicadores do nascimento da área.

Ainda, diferentes autores, consideram que o berço da Ciência da Informação foi os Estados Unidos. De acordo com essa premissa, entre os eventos que propiciaram o nascimento do novo campo de conhecimento, a Segunda Guerra Mundial foi o mais marcante, pois o desenvolvimento em ciência e tecnologia e da pesquisa no País se deu, muito, em função dessa guerra. Na perspectiva estadunidense, o artigo de Vannevar Bush, intitulado "As we may think", de 1945, é considerado por muitos pesquisadores como um marco da área por representar:

[...] o momento do pós-guerra em que se abriu um campo de investigação aos cientistas frente à questão da informação voltada para a identificação e para a solução de problemas informacionais, mediante aparatos tecnológicos, em particular, naqueles relativos à recuperação de informação (Rabello, 2008, p.22).

Para Rabello (2008, p.21), o artigo de Bush mostrou os primórdios da vocação que a Ciência da Informação tomou como conduta balizadora, ou seja,"Incitou a ênfase nos recortes teóricos de outras disciplinas para tentar suprir demandas específicas e aplicadas de informação (especializadas, portanto) em um enfoque marcadamente funcional e instrumental".

No contexto profissional, a concepção estadunidense de Ciência da Informação está relacionada às atividades profissionais em documentação e à eficiência organizativa de associações profissionais e de pesquisa, como o American Documentation Institute, fundado em 1937, e mais tarde transformado em American Society for Information Science (ASIS), diante da emergência e influência da Ciência da Informação. No ano de 2000, a ASIS acrescentou em seu nome a expressão and Technology, modificando a sigla para ASIS\&T. Essas as- 
sociações elegeram e disseminaram o termo Information Science para representar uma nova e promissora "ciência". O artigo de Borko (1968), embasado nas ideias de Taylor, ilustra bem a intenção de justificar e de delimitar essa nova disciplina, apresentando a mais conhecida das definições primeiras da Ciência da Informação que, por sua vez, foi resultante das preocupações teóricas discutidas nas conferências do Georgia Institute of Technology, realizadas nos EUA, em 1961 e 1962 (Rabello, 2008).

Borko (1968, p.3), em seu clássico artigo "Information science: What is it", define a Ciência da Informação como uma"Ciência interdisciplinar que estuda as propriedades e o comportamento da informação, as forças que governam seu fluxo e os meios de processá-la para otimizar sua acessibilidade e uso".

É importante destacar que não existe consenso entre os teóricos que defendem uma demarcação teórico-disciplinar para a Ciência da Informação. Alguns reconhecem na obra dePaul Otlet, "Traité de Documentation" de 1934, a base para uma perspectiva europeia da Ciência da Informação, considerando a documentação como a raiz disciplinar da Ciência da Informação. Portanto, para esses teóricos a Ciência da Informação surgiu com a perspectiva europeia, que seria considerada a vertente francófona. Outros, como Saracevic (1996), consideram que o artigo de Bush (1945) define o marco teórico inicial da Ciência da Informação, que se originou, assim, na perspectiva estadunidense, constituindo a vertente anglófona.

Mas, é a percepção estadunidense que vigora em grande parte das explanações conceituais da Ciência da Informação. Nessa percepção, uma das principais características dessa disciplina "Seria de lidar com os problemas informacionais pontuais e historicamente inscritos mediante o empréstimo de teorias comumente empregadas em outras disciplinas [...]" (Rabello, 2008, p.24). A partir dessa conceituação, a interdisciplinaridade faria parte de sua natureza constitutiva.

Uma vez que o caráter interdisciplinar da Ciência da Informação é reconhecido por grande parte dos teóricos da área, procurou-se destacar a questão da interdisciplinaridade na Ciência da Informação por meio das contribuições teóricas consideras mais significativas ao longo de mais de 40 anos de instauração da área.

\section{A interdisciplinaridade no campo da Ciência da Informação}

Antes de iniciar a discussão sobre a interdisciplinaridade na Ciência da Informação convém esclarecer qual o significado do termo interdisciplinaridade que esta se empregando no presente texto. Entende-se ser importante fazer essa distinção, pois várias são as terminologias que cercam o termo. Para equacionar a confusão terminológica Pombo (2005) propõe reconhecer o que há em comum em todas as definições, ou seja, o fato de estarem ligadas a uma mesma raiz que é a palavra "disciplina". Essa é, também, a opinião de Japiassu (1976), que, com relação à definição do termo "interdisciplinar", pondera que antes de se precisar uma delimitação é necessário, primeiramente, saber o que vem a ser uma disciplina. Japiassu (1976, p.59) apresenta vários critérios que podem ser aplicados para caracterizar a natureza de uma disciplina científica e conclui que "O que podemos entender por disciplina e por disciplinaridade é essa progressiva exploração científica especializada numa certa área ou domínio homogêneo de estudo"."Uma disciplina deverá, antes de tudo, estabelecer e definir suas fronteiras cons-tituintes". Portanto, "Falar de interdisciplinaridade é falar de interação de disciplinas".

Já Fazenda (1995, p.31), reconhecendo que a terminologia adotada é bastante vasta prefere seguir a tendência mais acentuada que se restringe a quatro conceitos básicos: pluri, multi, inter e transdisciplinaridade. Informa que "Em geral, existe uma gradação nesses conceitos, que se estabelece na esfera de coordenação e cooperação entre as disciplinas".

Pombo $(1994,2003)$ também trabalha as distinções entre pluri, multi, inter e transdisciplinaridade. No seu entender essas palavras são "Todas da mesma família" e "Devem ser pensadas num continuum que vai da coordenação à combinação e desta à fusão" (Pombo, 2003, p.3).

Assim, para quando se refere à pluridisciplinaridade ou multidisciplinaridade diz que "Estaríamos a pensar naquele primeiro nível que implica pôr em paralelo, estabelecer algum mínimo de coordenação". A interdisciplinaridade, por sua vez, já exigiria uma "Convergência de pontos de vista". A transdisciplinaridade remeteria a uma "Fusão unificadora, solução final que, 
conforme as circunstâncias concretas e o campo específico de aplicação, pode ser desejável ou não". Desse modo, o prefixo trans indicaria a "Passagem a um estado qualitativamente superior", enquanto que o prefixo inter, seria "Aquele que faz valer os valores da convergência, da complementaridade, do cruzamento [entre as disciplinas]" (Pombo, 2003, p.3).

Em meio a essa gradação, a interdisciplinaridade pode ser considerada como um fator de coesão entre saberes diferentes que rompe a estrutura de cada disciplina para construir uma axiomática nova e comum a todas elas. Em outras palavras, “É o intercâmbio mútuo e integração recíproca entre várias ciências", cuja cooperação resulta no enriquecimento recíproco (Pombo, 1994, p.2).

Nesse sentido, Pombo (1994) entende que a interdisciplinaridade ultrapassa a pluridisciplinaridade porque vai além da análise e confrontação das conclusões, elaborando uma síntese quanto aos métodos, leis e aplicações das disciplinas. Preconiza, assim, um regresso ao fundamento da disciplina, pois revela como a identidade do objeto de estudo se complexifica por meio dos diferentes métodos das várias disciplinas, explicitando a sua problemática e mútua relatividade.

Com base nas considerações de Pombo, Japiassu e Fazenda, considera-se que a interdisciplinaridade pressupõe a articulação de duas ou mais disciplinas em relação a um assunto, desse modo às disciplinas conversariam umas com as outras, visando apreender e partilhar os diversos domínios do saber.

Para focalizar a natureza interdisciplinar da Ciência da Informação vale-se dos estudos desenvolvidos por Pinheiro (2005, 2006a, 2006b), que mais tem se dedicado ao estudo das relações da Ciência da Informação com outras áreas, no Brasil, demarcando o processo evolutivo interdisciplinar da Ciência da Informação em três fases, a saber:

A primeira fase é considerada a fase conceitual e de reconhecimento interdisciplinar e abrange o período de 1961/1962 até 1969. Nesta fase Borko (1968), que na sua clássica definição de Ciência da Informação menciona as áreas com as quais esta tem um elo interdisciplinar, destacando a Biblioteconomia.
Essa primeira fase caracteriza-se pela ênfase na natureza disciplinar da área e pelas discussões em torno das suas denominações iniciais. Procura-se esclarecer a confusão terminológica com a informática, as origens e interfaces da área, principalmente com a Documentação, a Biblioteconomia e a Informática. Nessa fase surge, também, a preocupação com a cientificidade da área. Pinheiro (2006a, p.6) observa que por se tratar de um período de construção da área, "A maioria dos teóricos ainda não chega, nesse momento, a esclarecer qual e como se daria o aporte interdisciplinar de campo do conhecimento".

A segunda fase refere-se à delimitação do terreno epistemológico: princípios, metodologias e teorias próprios e influência das novas tecnologias e corresponde ao período de 1970 a 1989. Nesse período, "São estudados com maior profundidade, o objeto e a natureza da [Ciência da Informação], a presença da tecnologia no processo da área e o contexto de desenvolvimento científico daquele momento" (Bicalho, 2009, p.152). Nessa fase, merecem serem destacados os seguintes teóricos: Wersig e Nevelling (1975) e Foskett (1980).

Para Foskett (1980, p.56) existem definições e contextos que demonstram de forma clara as relações interdisciplinares da Ciência da Informação, pois ela é uma disciplina "Que surge de uma fertilização cruzada de ideias que incluem a velha arte da Biblioteconomia, a nova arte da Computação, as artes dos novos meios de comunicação", e as ciências como a Psicologia e a Linguística atualmente envolvidas com o processo e o problema da comunicação que dizem respeito à transferência da organização do pensamento.

Nesse período, um dos trabalhos considerados mais densos é o de Wersig e Nevelling (1975) que defendem a autonomia do campo científico que surge com a denominação "Ciência da Informação", o qual não teria se originado de outro campo de estudo, tampouco da interseção de dois ou mais campos, mas seria decorrente das necessidades de uma área de trabalho prático denominado "documentação" ou "recuperação da informação". Mas, reconhecem que a necessidade de informação permeia todos os grupos sociais e não somente aqueles diretamente ligados à produção de bens e serviços.

Os autores supracitados consideram que embora a introdução de novas tecnologias, particularmente do 
processamento eletrônico de dados, tenha determinado a emergência dessa disciplina, as contribuições para o nascimento da Ciência da Informação vieram de muitas disciplinas distintas consequência das diversas formações de especialistas que ingressaram no campo.

Wersig e Nevelling (1975) procuram descobrir quais foram as razões específicas que levaram ao desenvolvimento da Ciência da Informação, quais as necessidades sociais que preenche e, devido às dificuldades na discussão dos fenômenos que podem pertencer à Ciência da Informação, recomendam sistematizar os diferentes pontos de vista dentro de quatro categorias: 1) A visão orientada para o fenômeno; 2) A visão orientada para os meios; 3) A visão orientada para a tecnologia; 4) A visão orientada para os fins.

Desse modo, Wersig e Nevelling (1975), ampliam os limites da atuação da Ciência da Informação, lançando um novo olhar sobre seu próprio campo científico.

A terceira fase, a partir de 1991, é vista como a etapa de consolidação da denominação e de alguns princípios, métodos, teorias e aprofundamento da discussão sobre interdisciplinaridade com outras áreas. Nesse período os temas discutidos centraram-se nos aspectos relativos à organização interna da área e sua institucionalização. As reflexões ocorridas na reunião de Tampere, na Finlândia, em 1991, sobre "Concepções da Ciência da Informação e da Biblioteca: perspectivas históricas, empíricas e teóricas", cujos anais foram publicados por Vakkari e Cronin (1992), contribuíram de forma significativa para elucidar questões importantes relativas às conexões interdisciplinares da área.

Saracevic $(1995,1996)$ vem, desde a década de 1970, discutindo a origem e evolução da Ciência da Informação, enfocando os problemas surgidos ao longo do tempo, seu papel social na progressiva transformação da sociedade e examinando suas relações interdisciplinares.

Saracevic (1995) aponta três características gerais que constituem a Ciência da Informação: interdisciplinaridade, ligação com a tecnologia de informação e, por último, uma participação ativa e deliberada na evolução da sociedade da informação.

Com relação à abordagem interdisciplinar, considera que a natureza da Ciência da Informação é interdisciplinar, contudo essas relações são dinâmicas e podem ser mais fortes em um determinado tempo e espaço com algumas áreas científicas.

Quanto à segunda característica, ligação com a tecnologia de informação, Saracevic (1995) pensa que essa ligação é inexorável porque o componente tecnológico está impulsionando e forçando a evolução da Ciência da Informação, assim como a evolução da sociedade da informação.

Por fim, Saracevic (1995) julga que a Ciência da Informação tem uma participação ativa e deliberada na evolução da sociedade da informação, com uma forte dimensão humana e social. Com essa sugestão Saracevic (1995) resgata a ideia de uma responsabilidade social para a Ciência da Informação, proposta por Wersig e Nevelling (1975). Essas três características, segundo Saracevic (1995), compõem um quadro para a compreensão do passado, presente e futuro da Ciência da Informação.

Bicalho (2009) identifica em Savolainen (1992) mais uma fase na reunião de Tampere. Considera que:

De certa forma Savolainen (1992) sugere a quarta fase, em perspectiva, quando se refere ao crescimento das pesquisas multidisciplinares, como pesquisas de busca e uso de informação, cruzadas com Psicologia Cognitiva, Inteligência Artificial, Ciência da Computação, Filosofia, Matemática, Semântica e Linguística, entre outras, o que, segundo ele, levaria ao fortalecimento da pesquisa em Cl [Ciência da Informação], por meio de relações mais próximas com outras disciplinas (Bicalho, 2009, p.45).

Contudo, Bicalho (2009) considera que"Qualquer que seja a fase em que a Ciência da Informação se enquadre, neste início do século XXI, é certo que a área seja caracterizada por fundamentos teóricos e práticas que foram desenvolvidos ao longo de sua história".

Pelo exposto pode-se perceber que a delimitação do campo de atuação da Ciência da Informação é uma preocupação recorrente entre os estudiosos da área, no sentido de facilitar e propiciar "As relações de reconhecimento e complementaridade com outras disciplinas", de acordo com González de Gómez (2000, p.2).

As fases demarcadas por Pinheiro (2005, 2006a, 2006b) evidenciam que a Ciência da Informação tem se preocupado em definir sua identidade e seus limites, ou 
seja, a comunidade científica da área tem buscado, primeiramente, clarificar seus fundamentos teóricos e conceituais para depois estabelecer pontes e fronteiras com outras disciplinas.

Com base nos estudos teóricos mencionados, examinou-se o relacionamento da Ciência da Informação com a Biblioteconomia, uma das áreas mais citadas na literatura que analisa a interdisciplinaridade da Ciência da Informação e muito próxima da sua constituição histórica.

\section{A Ciência da Informação e as relações interdisciplinares com a Biblioteconomia}

Dentre as disciplinas com as quais a Ciência da Informação mantém relações interdisciplinares, a Biblioteconomia é apontada na literatura como aquela que apresenta um forte laço interdisciplinar com a área.

Como afirma Saracevic (1996, p.49) o"Campo entre a Biblioteconomia e a Ciência da Informação é intenso a ponto de serem confundidas como uma única área". Considera, portanto, que isso se deve ao compartilhamento de sua missão social e sua preocupação comum com os problemas da efetiva utilização dos registros. Mas, diz também que existem diferenças bastante significativas em alguns aspectos críticos, como por exemplo:

a) na seleção dos problemas propostos e a forma de sua definição;

b) nas questões teóricas colocadas e nos modelos explicativos introduzidos;

c) na natureza e no grau de experimentação e desenvolvimento empírico,

d) assim como no conhecimento prático ou competências derivadas;

e) nas ferramentas e abordagens utilizadas;

f) na natureza e na força das relações interdisciplinares estabelecidas e sua dependência para o avanço e evolução das abordagens interdisciplinares.

Apesar das diferenças apontadas, Saracevic (1996) considera que a relação da Biblioteconomia com a Ciência da Informação, em relação a outras áreas, é a mais significativa e desenvolvida, mas isso não significa que formem um único campo de conhecimento.
Shera (1980, p.102) também entende que das tantas áreas com que a Ciência da Informação se relaciona sem dúvida a ligação mais estreita é com a Biblioteconomia. Após examinar a relação da Ciência da Informação com a Biblioteconomia, tendo por base um estudo efetuado por Taylor (1967), conclui que "a Ciência da Informação não se opõe à Biblioteconomia, ao contrário, ambas as disciplinas são aliadas naturais [...]".

Vakkari (1994) reconhece que as relações entre a Biblioteconomia e a Ciência da Informação há muito tempo vêm sendo discutidas, mas considera que subsiste alguma incerteza acerca dessa relação. Para ele, existem duas concepções básicas a respeito do relacionamento entre essas disciplinas: a primeira julga que elas podem ser vistas como duas disciplinas separadas, com alguns interesses em comum; a segunda variante é ver uma como parte da outra, ou seja, como um único conjunto.

Quanto à questão da Biblioteconomia e da Ciência da Informação ser campos distintos, Vakkari (1994) argumenta que historicamente é inegável que a Biblioteconomia nasceu antes da Ciência da Informação ou de sua antecessora, a Documentação.

Na visão de Vakkari (1994), historicamente a diferença entre Biblioteconomia e Documentação se cristaliza na noção de que cabe a Biblioteconomia prover o acesso aos registros gráficos nas bibliotecas enquanto que a Documentação facilita o acesso aos documentos em qualquer formato, independente da instituição. Isso significa que a Biblioteconomia está ligada a certo tipo de documento e instituição, mas a Documentação focaliza sua atenção em todos os tipos de documentos e instituições que os transmitem. Contudo, ambas têm uma característica comum que é facilitar o acesso à informação.

Na discussão sobre a concepção da Biblioteconomia e da Ciência da Informação como um único campo, Vakkari (1994) se apóia nos argumentos de alguns autores, dos quais se destaca Ingwersen (1992) e Wersig (1992).

Wersig (1992) é o autor que apresenta uma opinião mais radical sobre essa questão porque nega a existência da Biblioteconomia como ciência. Na Conferência Internacional de Tampere, ocorrida na Finlândia em 1991, discute a constituição teórica da área de Ciência 
da Informação e argumenta que mesmo sendo convencido de que há boas razões para falar da Biblioteconomia como ciência e boas razões para falar da Ciência da Informação nesse mesmo sentido, ainda assim objetaria que as duas formam um único conjunto.

Na realidade, Wersig (1993) considera que a Ciência da Informação não é uma ciência clássica, imaginando-a como um protótipo de ciência pós-moderna. O autor entende que a emergência do campo decorre da necessidade de se criar estratégias para solucionar problemas causados pela ciência e tecnologia. A visão de Wersig (1993) está pautada na importância que o conhecimento passa a exercer no mundo contemporâneo, principalmente nas dimensões científica e tecnológica. Nesse contexto, considera a Ciência da Informação um novo tipo de disciplina e questiona sua organização como disciplina tradicional, enfatizando a necessidade de uma construção teórica que dê conta dessa nova complexidade. Nesse sentido, reconhece a interdisciplinaridade da Ciência da Informação com diferentes áreas, principalmente com a Biblioteconomia.

Ingwersen (1992) diz que existem argumentos que consideram a Biblioteconomia como uma disciplina independente ou talvez um paradigma concorrente para a Ciência da Informação. Em sua opinião isso pode acontecer, dependendo do ponto de vista adotado, mas que, tradicionalmente, a Biblioteconomia tem apresentado um forte impacto na Ciência da Informação. Ele também usa Ciência da Informação como um termo genérico e vê a Biblioteconomia como uma atividade especial de pesquisa e desenvolvimento dentro da Ciência da Informação. Na sua visão, a Biblioteconomia está relacionada com os processos de informação que têm lugar nas bibliotecas. Sua ideia é usar a Ciência da Informação como um termo genérico e esboçá-la como um campo de pesquisa mais amplo. Desse modo, os problemas da disciplina a respeito da Biblioteconomia formam um campo aplicado especial de pesquisa. Considera que se poderia também indicar que as bibliotecas são um campo de aplicação para a pesquisa em Ciência da Informação.

Os pontos de vista de Ingwersen (1992) e Wersig (1993) convergem, portanto, para a noção de que a Biblioteconomia e a Ciência da Informação são campos próximos, mas que os dois termos não deveriam ser utilizados em conjunto para significar um mesmo campo.
No Brasil, além dos estudos de Pinheiro (2005, 2006a, 2006b), já mencionados neste texto, pode-se localizar algumas contribuições significativas que intentam esboçar as relações centrais e conceitos básicos da Ciência da Informação, assim como suas relações interdisciplinares.

González de Gómez $(2001$, p.5) considera que a constituição do campo científico denominado Ciência da Informação "Sempre foi uma questão em aberto". Considera, contudo, que nos últimos anos, o campo "[tem] explorado, [...], um pluralismo metodológico próprio das Ciências Sociais e de um campo interdisciplinar". Na sua concepção, a Ciência da Informação"Integra, junto com a epistemologia, um campo de explicitação de formações sociais de meta-conhecimento [...]", a organização do conhecimento, numa interseção da Biblioteconomia com a Ciência da Informação, poderia ser uma dessas abordagens do meta-conhecimento. Ainda, "Esta característica justifica [...] a orientação interdisciplinar ou transdisciplinar do campo, na medida em que este se vê obrigado a trabalhar na articulação das dimensões plurais do objeto informacional". Portanto, considera que uma situação interdisciplinar ocorreria quando, para a resolução de um problema, é exigida a coocorrência de diferentes saberes. Desse modo, "A situação interdisciplinar é o resultado de um acontecimento, o encontro interdisciplinar, que se constitui pela interrogação acerca de um problema".

Smit et al. (2004), em pesquisa que se propõe a refletir sobre os critérios científicos que pautaram a constituição da Ciência da Informação, por meio da análise da terminologia da área, obtiveram duas ordens de conclusões: a primeira diz respeito à terminologia utilizada pela área; a segunda, gerada a partir da primeira, concerne à identidade da área. Para fins deste texto, ressalta-se alguns pontos relativos à segunda ordem de conclusões.

Com relação à identidade da Ciência da Informação, Smit et al. (2004, p.1) concluíram, entre outras descobertas, que"Boa parte das noções sedimentadas pelaárea denominam procedimentos oriundos da Biblioteconomia". Dessa forma, consideram que se pode vislumbrar um eixo evolutivo para a área que "Se inicia na Biblioteconomia, da qual, ou contra a qual - surge a Documentação, mas que não a substitui". Por sua vez, a Ciência da 
Informação "Surge no pós-guerra, com múltiplas definições e abrangências" [...].

De modo geral, a literatura identifica a constituição da área na interdisciplinaridade, associando-a a uma reunião de diferentes disciplinas. Isso ocorre, segundo Smit et al. (2004, p.1), porque o termo Ciência da Informação "Não se define pelo queé, mas pelas possíveis apropriações que realiza em campos do saber, estabelecidas, via de regra, por associações dependentes do problema investigado", por exemplo: para questões relativas ao usuário, recorre-se à Psicologia; se a questão é de informática documentária, busca-se a Informática; se é de administração de sistemas, emprega-se a Teoria da Administração, e assim sucessivamente.

Oliveira e Carvalho (2009, p.11) em pesquisa que teve por objetivo identificar as relações interdisciplinares, no âmbito do ensino, entre a Biblioteconomia e a Ciência da Informação, concluíram que é preciso "Refletir mais e constantemente sobre as trocas realizadas e as incorporações conceituais e metodológicas. Para que se evite a assimilação de forma acrítica e com isso o seu possível enfraquecimento". Acreditam, ainda, que "A comunidade científica tem trabalhado em demasia nos espaços fronteiriços da Ciência da Informação". Dessa maneira, a busca pela interdisciplinaridade, sem muita reflexão e entendimento, pode estar tornando a área vulnerável em vez de resolver sua fragmentação.

Por fim, para Pinheiro (2006a, p.6) a Ciência da Informação"Tem reconhecida a sua interdisciplinaridade desde o seu aparecimento" e a relação com a Biblioteconomia "Tem sua origem no movimento da documentação dos anos 60", especialmente "Nas Escolas de Biblioteconomia, cujo objetivo era melhorar a técnica, o conteúdo intelectual dos registros e seu uso e a aplicação de tecnologias nas funções tradicionais de bibliotecas". Desse modo, reconhece as relações interdisciplinares entre as duas áreas, mas reafirma a"Independência científica da Ciência da Informação, com seu próprio estatuto científico" (Pinheiro, 2005, p.7).

Como se observa a maioria dos autores admite a existência de uma estreita relação entre a Biblioteconomia e a Ciência da Informação. Mas, apesar dos reconhecimentos de fortes laços interdisciplinares entre os dois campos, acredita-se, como Wersig, Ingwersen e
Pinheiro, que são campos distintos e que os dois termos não devem ser utilizados para significar um mesmo campo.

\section{Considerações Finais}

O conjunto de reflexões até aqui apresentadas evidencia que a Ciência da Informação é uma área potencialmente interdisciplinar uma vez que nasceu em um momento de reconfiguração da ciência moderna e vem tentando se estabelecer como um novo ramo que objetiva estudar os fenômenos ligados à produção, organização, difusão, acessibilidade e uso do conhecimento em variados contextos.

A Biblioteconomia desde sua origem está intrinsecamente ligada à biblioteca e seu problema central sempre se constituiu no tratamento e no provimento do acesso aos registros gráficos. Mas, devido ao aumento exponencial no acervo do conhecimento da humanidade, a chamada explosão informacional, a Biblioteconomia foi impelida a ampliar e aprofundar as observações e análises relativas aos problemas da área por intermédio da assimilação de recursos de outros campos de conhecimento que Ihe permitissem estudar e entender a produção e o registro de informações, seu armazenamento em diversos suportes, a organização para seu acesso, o processo de recuperação e as consequências socioculturais de seu uso.

Percebe-se pela análise efetuada que a maioria dos autores reconhece uma estreita relação entre a Biblioteconomia e a Ciência da Informação, chegando alguns a admitir que possam ser confundidas como uma única área. Já outros, reconhecem que a Ciência da Informação se inicia na Biblioteconomia. Contudo, os fatos históricos mostram que a Biblioteconomia nasceu antes da Ciência da Informação.

Reconhece-se que a Biblioteconomia e a Ciência da Informação têm uma característica comum: facilitar o acesso à informação e ao conhecimento. Considera-se, portanto, que a partir desse elo comum podem conversar uma com a outra, apreendendo e partilhando conhecimentos.

A possibilidade do diálogo entre as disciplinas é a condição primeira para a prática efetiva da interdisciplinaridade, mas para que isso aconteça com sucesso 
e as disciplinas "dialoguem", é necessário que existam representantes qualificados de cada uma delas. É importante que os profissionais estejam abertos ao diálogo, que consigam identificar o que lhes falta e o que podem receber dos outros. Essa atitude só é adquirida quando se propõe uma abertura no desenvolvimento do trabalho em uma equipe interdisciplinar. Nesse contexto, a interdisciplinaridade não se apresenta simplesmente como um conceito teórico, mas como uma prática individual.

Apesar de se defender a ideia de que a Biblioteconomia e a Ciência da Informação são campos distintos, não se excluí a possibilidade do exercício interdisciplinar entre as disciplinas. $O$ ponto de partida dessa relação é procurar identificar o que cada disciplina estuda e suas relações comuns de trabalho para poder relacionar as familiaridades e extrair suas conexões recíprocas. Percebe-se, pela análise efetuada, que a prática interdisciplinar entre as duas áreas ainda é tênue, pois todos os autores mencionados evidenciaram essa interação somente no plano teórico, não descreveram interações no plano prático.

Desse modo, seria muito proveitoso, tanto para a academia, como para a aplicação profissional, traçar um quadro de teorias e metodologias utilizadas pela Ciência da Informação e pela Biblioteconomia, a fim de estabelecer que pontos são tratados em comum e quais são específicos em cada área.

Espera-se com as reflexões aqui emitidas, motivar os pesquisadores da Biblioteconomia e da Ciência da Informação a viver e exercer a interdisciplinaridade a fim de buscar um efetivo diálogo e uma efetiva harmonização das duas áreas, pois, não se deve esquecer que os estudos interdisciplinares são uma exigência do mundo contemporâneo, possibilitando aos pesquisadores um conhecimento maior sobre as transformações ocorridas, permitindo novas atitudes que possibilitem maior integração, produzam novos conhecimentos e consequentemente novos projetos.

É necessário entender que atualmente vive-se uma fase de transição paradigmática que afeta principalmente a educação, portanto esse é o momento que favorece o pensar interdisciplinar. Olhar o futuro de forma global, mas atentos ao presente, é edificante para desenvolver o otimismo com coragem e enfrentamento para criar o futuro.

\section{Referências}

Bicalho, L.M. As relações interdisciplinares refletidas na literatura brasileira de ciência da informação. 2009. Tese (Doutorado em Ciência da Informação) - Escola de Ciência da Informação, Universidade Federal de Minas Gerais, 2009.

Borko, H. Information science. What is it? American Documentation, v.19, n.1, p.3-5, 1968.

Bush, V. As we may think. Atlantic Monthly, v.176, n.1, p.101-108, 1945.

Fazenda, I.C.A. Interdisciplinaridade: um projeto em parceria. 3.ed. São Paulo: Edições Loyola, 1995.

Foskett, D.J. Ciência da informação como disciplina emergente: implicações educacionais. In: Gomes, H.E. (Org.). Ciência da informação ou informática? Rio de Janeiro: Calunga, 1980. p.53-69.

González de Gómez, M.N. Metodologia de pesquisa no campo da ciência da informação. DataGramaZero, v.1, n.6, p.1-11, 2000. Disponível em: <http://www.dgz.org.br>. Acesso em: 14 ago. 2010.

González de Gómez, M.N. Para uma reflexão epistemológica acerca da ciência da informação. Perspectivas em Ciência da Informação, v.6, n.1, p.5-18, 2001.

Ingwersen, P. Conceptions of information science. In: Vakkari, P.; Cronin, B. (Ed.). Conceptions oflibrary and information science:

Historical, empirical and theoretical perspectives. London: Taylor Graham, 1992. p.299-311.

Japiassu, H. Interdisciplinaridade e patologia do saber. Rio de Janeiro: Imago, 1976.

Oliveira, M.; Carvalho, F. A interlocução entre a bibliote-conomia e a ciência da informação: um foco interdisciplinar. In: Encontro Regional dos Estudantes de Biblioteconomia, Documentação, Ciência da Informação e Gestão Documental, 10., 2009, Goiânia. Anais... Goiânia: UFG, 2009. p.1-13.

Pinheiro, L.V.R. Evolução e tendências da ciência da informação no exterior e no Brasil: quadro comparativo a partir de pesquisas históricas e empíricas. In: Encontro Nacional de Pesquisa em Ciência da Informação, 6., 2005. Anais... Florianópolis: Enancib, 2005. p.1-12.

Pinheiro, L.V.R. Movimentos interdisciplinares e rede conceitual na ciência da informação. Encontro Nacional de Pesquisa em Ciência da Informação, 7., 2006, Marília. Anais... Marília: Enancib, 2006a. p.1-12. Disponível em: <http://www.portalppgci. marília.unesp.br>. Acesso em: 8 ago. 2010.

Pinheiro, L.V.R. Ciência da informação: desdobramentos disciplinares, interdisciplinaridade e transdisciplinaridade. In: González de Gómez, M.N.; Orrico, E.G.D. (Org.). Políticas de memória e informação: reflexos na organização do conhecimento. Natal: UFRN, 2006b. p.111-141. 
Pombo, O. Contribuição para um vocabulário sobre interdisciplinaridade. In: Pombo, O.; Levy, T.; Guimarães, H. (Org.). A interdisciplinaridade: reflexão e experiência. 2.ed. Lisboa:Texto, 1994. p.5-12.

Pombo, O. Epistemologia da interdisciplinaridade. In: Pimenta, C. (Coord.). Interdisciplinaridade, humanismo, universidade. Porto: Campo das Letras, 2003. Disponível em: <http.//www. educ.fc.ul.pt/docentes/opombo/investigação/portofinal. pdf>. Acesso em: 3 mar. 2013.

Pombo, O. Interdisciplinaridade e integração dos saberes. Liinc em Revista, v.1, n.1, p.3-15, 2005. Disponível em: <http:// www.ibict.br/liinc>. Acesso em: 3 mar. 2013.

Rabello, R. História dos conceitos e ciência da informação: apontamentos teórico-metodológicos para uma perspectiva epistemológica. Encontros Bibli, n.26, p.17-46, 2008.

Santos, A.P.L. Relações interdisciplinares entre a ciência da informação e a biblioteconomia: limites e possibilidade. 2012. Dissertação (Mestrado em Ciência da Informação) - Universidade Federal Fluminense, Niterói, 2012.

Saracevic, T. Interdisciplinary nature of information science. Ciência da Informação, v.24, n.1, p.36-41, 1995.

Saracevic, T. Ciência da informação: origem, evolução e relações. Perspectivas em Ciência da Informação, v.1, n.1, p.41-62, 1996.

Savolainen, R. The sense-making theory: An alternative to intermediary-centered approaches in library and information science? In: Vakkari, P.; Cronin, B. (Ed.). Conceptions of library and information science: Historical, empirical and theoretical perspectives. London: Taylor Graham, 1992. p.149-164.

Shera, J.H. Sobre a biblioteconomia, documentação e ciência da informação. In: Gomes, H.E. (Org.). Ciência da Informação ou informática? Rio de Janeiro: Calunga, 1980. p.91-105.

Smit, J.W.; Tálamo, M.T.G.; Kobashi, N.Y. A determinação do campo científico da ciência da informação: uma abordagem terminológica. DataGramaZero: Revista de Ciência da Informação, v.5, n.1. p.1-10, 2004. Disponível em: <http://www. dgz.org.br>. Acesso em: 3 mar. 2013.

Taylor, R.S. The interface between librarianship and information science and engineering. Special Libraries, v.58, p.45-48, 1967.

Vakkari, P. Library and information science: Its content and scope. Advances in Librarianship, v.18, p.1-55, 1994.

Vakkari, P.; Cronin, B. (Ed.). Conceptions of library and information science: Historical, empirical and theoretical perspectives. London: Taylor Graham, 1992.

Wersig, G. Information science and theory: A weaver bird's perspective. In:Vakkari, P.; Cronin, B. (Ed.). Conceptions oflibrary and information science: Historical, empirical and theoretical perspectives. London: Taylor Graham, 1992. p.201-217.

Wersig, G. Information science: the study of postmodern knowledge usage. Information Processing \& Management, v.29, n.2, p.229-239, 1993.

Wersig, G.; Nevelling, U. The phenomena of interest to information science. The Information Scientist, v.9, n.4, p.127-140, 1975. 